\title{
Histological Features of Oral Cavity Mucous Membrane Epithelium in Six-Month-Old Experimental Animals Born with Macrosomia
}

\author{
Olga Garmash ${ }^{1, *}$, Galina Gubina-Vakulik¹, David Vondrášek²
}

\begin{abstract}
We examined the histological features of the mucobuccal fold of oral cavity mucous membrane from the area of the masticatory teeth roots' projection in 6-month-old Wistar Albino Glaxo rats with fetal macrosomia. The animals were divided into groups according to the body weight, the body length, and the Quetelet index at birth. A morphological study was performed using the Leica SP8 AOBS laser scanning confocal microscope and a conventional light (Axiostar, Zeiss) microscopy. Morphometric parameters were used to estimate the degree of acanthosis development in the epithelium of the oral mucosa, which indicates the intensity of its proliferation. Numerous narrow and deep acanthotic outgrowths and densely located 'juvenile' epitheliocytes in the basal layer on the apex of the acanthotic protrusions were found in animals with fetal macrosomia that was due to intrauterine obesity. In these animals, the morphometric index, which we used, was maximally different from that in the control group. In animals with fetal macrosomia that was due to intrauterine growth acceleration of the body, the hyperproliferation of the mucous membrane epithelium of the oral cavity was absent or little pronounced. It can be assumed that fetal macrocosmia with obesity causes instability in the epithelium of the oral cavity mucosa, its rapid death, and therefore, a more active stimulation of proliferation.
\end{abstract}

\section{KEYWORDS}

fetal macrosomia; experimental animal; oral mucous membrane; confocal microscopy

AUTHOR AFFILIATIONS

${ }^{1}$ Kharkiv National Medical University, Therapeutic Dentistry Department, Ukraine

2 Institute of Physiology of the Czech Academy of Sciences, Department of Biomathematics, Czech Republic

* Corresponding author: Kharkiv National Medical University, Therapeutic Dentistry Department, 61174, 51 Peremogy avenue, The Stomatological Centre of KhNMU, Ukraine; e-mail: o.v.garmash@gmail.com

Received: 21 June 2018

Accepted: 11 November 2018

Published online: 22 January 2019

Acta Medica (Hradec Králové) 2018; 61(4): 137-143

https://doi.org/10.14712/18059694.2018.132

(c) 2018 The Authors. This is an open-access article distributed under the terms of the Creative Commons Attribution License (http://creativecommons.org/licenses/by/4.0), which permits unrestricted use, distribution, and reproduction in any medium, provided the original author and source are credited. 


\section{INTRODUCTION}

During the last decade, a particular attention has been given to studying the characteristic features of the intrauterine development of tissues and organs. The violation of these processes predisposes further development of a number of diseases.

The violation of adaptation processes and the aberration in physical, somatic, or neuropsychic states arise as a consequence of intrauterine sufferings. The hypothesis about fetal or intrauterine programming is termed the metabolic memory (1), when the changes that are downloaded during the intrauterine period are programming a predisposition towards certain diseases in the future ontogenesis has been confirmed in a few studies.

Fetal macrosomia or large birth weight is a well-studied scientific and practice clinical subject $(2,3,4)$. It is well known that children with fetal macrosomia have high risk of obesity, high blood pressure, a high blood sugar level, and, as a consequence, the appearance of diabetes mellitus and cardiac diseases later in life $(5,6)$. Some scientists $(7)$ emphasize an increased risk of the appearance of cancer diseases. Hermann GM and coauthors (8) studied the risk of metabolic syndrome formation in the adult life. The violations of the menstrual cycle, dyshormonal changes in mammary glands, sterility, and the formation of neoplastic diseases are characteristic of the females who born with macosomia (9).

The features of clinical, metabolic and immunological adaptations of such newborns have also been represented in numerous studies conducted by Kharkiv National Medical University scientists $(10,11,12)$.

However, there is insufficient knowledge about the dental aspect of macrosomia $(13,14,15)$. We also think that fetal macrosomia is a risk factor for the formation of certain oral cavity diseases, and we have already revealed dental violations in people born with macrosomia in our previous studies $(16,17,18,19)$.

Morphological data analysis is a first step in investigating the postnatal genesis features of oral cavity mucosa in species that were born macrosomic. The adequate evaluation of the functional and morphological condition of oral cavity mucosa is significant for successfully solving the diagnostic issues of diseases of the oral cavity at a pre-clinical manifestation stage. This evaluation also increases the efficiency of a clinical course prognosis.

One of the most informative methods that allow the study of all mucosa structures in detail is confocal microscopy (20, $21,22,23)$. Successively obtained images of the different layers allow us both to reconstruct a 3-D structure and to perform quantitative analysis of the sample (24). The 3-D reconstruction of a section of oral cavity mucosa in experimental animals is useful for evaluating the condition of the tissues.

Taking into account close coupling between the state of oral cavity mucosa and the appearance of dental violations, the experimental modeling of fetal macrosomia has been conducted. Analysis of the data obtained in this experiment elucidates some pathogenic links in the intrauterine formation of dental diseases in the case of fetal macrosomia. The results obtained also form a basis for substantiating, developing, approbating, and the further implementation in pathogenetically targeted treatment and prevention. Therefore, experimental studies of oral cavity mucosa featured in species born with a body weight large for the gestational age are of interest for components of pathogenesis of pathological processes in their oral cavity.

The aim of this paper is to study the histological features of oral cavity mucosa, viz. mucobuccal fold epithelium, in rats with fetal macrosomia (groups under study) and in rats after normal intrauterine development (Control Group).

\section{MATERIAL AND METHODS}

The study was carried out by research fellows in the Departments of Therapeutic Dentistry and Pathological Anatomy at Kharkiv National Medical University and by research fellows in the Department of Biomathematics, Institute of Physiology of the Czech Academy of Sciences.

Subjects. The macrosomia formation experiment was conducted to examine the histological features of oral cavity mucosa from the mucobuccal fold taken off the projection area of molar roots in 6-month old Wistar Albino Glaxo (WAG) rats with fetal macrosomia. In all experiments the WAG rats aged 180 days were used. The utilization of outbreed rats in these experiments permits the reproduction of the data being obtained in repeated studies. In addition, the reasons for utilizing WAG rats are rapid metabolism, short-term pregnancy and the offsprings reaching adulthood rapidly. The choice of WAG rats was due to the fact that this line is universal, not strictly specific, and it was possible to obtain an increased number of macrosomic pups due to the proposed models of macrosomia formation. We were not interested in genetically programmed animals for rapid intrauterine lengthening and rapid intrauterine body weight gain.

Caring and using the experimental animals meet the requirements of the National General Ethical Principles of Ethical Conduct in the Care and Use of Animals (Ukraine, 2001), which are in agreement with the provisions of "European Convention for the Protection of Vertebrate Animals used for Experimental and other Scientific Purposes" (Strasbourg, 1986).

Experimental procedures. The standard clinical criterion (body weight in excess of the 90th percentile level) within a large number (500) of newborn rats was used to diagnose macrosomia. All groups had a roughly comparable ratio of male to female animals. The animals were divided in five groups (of 5-6 animals in each group) according to their body weight, the body length, and the Quetelet index at birth.

Four different models were used for macrosomia formation:

(1) Physical Development Acceleration Model: The oversized ( $m \geq 6.3 \times 10^{-3} \mathrm{~kg}$ ) pups of young ( $3-5$ month-old) animals with average weight-height parameters and the standard nutrition ration ( $4 \mathrm{kcal} / \mathrm{g}, 5 \% \mathrm{fat}$ ) before zoogamy and during pregnancy were used (8). In this group, $10 \%$ offspring rats were born macrosomic.

(2) Young + Diet Model: The oversized pups of young (3-5 month-old) animals with average weight-height parameters and the high-calorie diet ( $5 \mathrm{kcal} / \mathrm{g}$ ) $45 \%$ fat, 35\% carbohydrates and $20 \%$ protein before zoogamy and during pregnancy were used (Gubina-Vakulik GI 1994) (25). The data on the content of nutritional substances and a diet energy value (D12451; Research Diets, New Brunswick, N.J., USA) were 
found in (8). Fetal macrosomia was obtained in $12 \%$ of rats when this model was used.

(3) Mature + Diet Model: The oversized pups of middle aged (8-9 month-old) animals with average weight-height parameters and the high-calorie diet (5 kcal/g) 45\% fat, 35\% carbohydrates and $20 \%$ protein before zoogamy and during pregnancy (Gubina-Vakulik GI 1994) were used (25). Fetal macrosomia was obtained in $17 \%$ of rats when this model was used.

(4) Hypokinetic + Diet Group Model: The oversized pups of young (3-5 month-old) animals with average weight-height parameters and the high-calorie diet (5 kcal/g: 45\% fat, 35\% carbohydrates and $20 \%$ protein) before zoogamy and during pregnancy, which were kept in mild hypokinetic conditions, were used (26). In the model used, the hypokinetic conditions were light, namely, to lower motion activity, an animal was place into a $20 \mathrm{~cm} \times 20 \mathrm{~cm} \times 25 \mathrm{~cm}$ cage, which was by a factor of 3 greater than the animal's size. The rat specimen whose birth weight exceeded the 90th percentile level $\left(m \geq 6.3 \times 10^{-3} \mathrm{~kg}\right)$ were ranged in Group 4. This way of modeling macrosomia resulted in $30 \%$ of macrosomic offsprings.

All offspring rats were maintained on standard balanced diet, had free access to tap water, and were held under the principles of Good Laboratory Practice.

Group $\mathbf{1}(\mathbf{n}=\mathbf{5})$ contained macrosomic animals (whose birth weight exceeded the 90th percentile level), with an increased intrauterine body outgrowth rate, with a relatively decreased body weight, and with a relatively decreased Quetelet index at birth (offsprings with intrauterine stimulation of growth processes);

Group $2(n=6)$ contained macrosomic animals with intrauterine obesity (relatively small body length and large body weight);

Group $3(n=6)$ contained macrosomic animals whose intrauterine weight gain rate and height rate are harmonious;

Group $4(\mathbf{n}=\mathbf{6})$ included macrosomic animals with intrauterine obesity, whose mothers were kept under hypokinetic conditions during their pregnancy (Hypokinetic + Diet Group Model);

Group $\mathbf{5}(\mathbf{n}=\mathbf{5})$ (Control Group) contained animals with average weight-height parameters at birth (birth weight was within one standard deviation from the median body weight), whose mothers had the standard nutrition ration $(4 \mathrm{kcal} / \mathrm{g}$,
$5 \%$ fats) and their pregnancy passed under common conditions. The offsprings from different litters were used to form each of the groups.

The somatometric examination of the rats (weighing, measurement of body length, and tail length) was conducted twice: at birth and immediately before withdrawing animals from the experiment (Table 1 ).

In Table 1, the primary examination refers to the data acquired for the one-day-old rats, and the secondary examination refers to the data acquired for the same rats aged 180 days.

For the study, we used tissues of oral mucosa. In each animal, the samples were taken off the same topographic areas, namely the mucobuccal fold taken off the area of upper and lower jaw molar roots' projection.

The histological sections of mucosa, 5-6 $\mu \mathrm{m}$ thick, were stained with hematoxylin and eosin, Einarson's gallocyanin-chrome alum, and Van Gieson's stain. They were examined with the PSA method.

One of the purposes of this study was to estimate the proliferation activity of the epithelium in the oral cavity mucosa by means of counting the average number of acanthotic outgrowths per microsection unit length, and measuring the depth of the acanthosis. To achieve this goal, the sections of oral cavity mucosa, 20-70 $\mu \mathrm{m}$ thick, stained by hematoxylin and eosin (H\&E), were used.

The morphological study was performed using a conventional light (Axiostar, Zeiss) microscopy and confocal microscopy.

Confocal Microscopy. The Leica SP8 AOBS laser scanning confocal microscope (LSCM) at the inverted Leica DMi8 microscope stand installed in the Department of Biomathematics, Institute of Physiology, Czech Academy of Sciences (Prague, Czech Republic) was used to acquire the image data.

The Argon (488 nm) laser, which is part of the microscope, was used in the single-photon excitation mode. The maximum power of the laser at the sample focal plane of ACS APON $40 \times 1.15$ Oil CS lens was $0.27 \mathrm{~mW}$. Leica power setting during sample acquisition was set to $2.5 \%$ in order to avoid photobleaching of the sample and the saturation of an image. We optimized the setting of excitation and detection wavelengths for $\mathrm{H} \& \mathrm{E}$ imaging as follows. First, using an excitation wavelength of $488 \mathrm{~nm}$, the detection range was optimized

Tab. 1 Results on morphometric studies of test animals.

\begin{tabular}{|c|c|c|c|c|c|c|}
\hline \multirow[t]{2}{*}{$\begin{array}{l}\text { Groups under } \\
\text { study }\end{array}$} & $\begin{array}{l}\text { Average body } \\
\text { weight } \\
\left(\mathrm{kg} \times 10^{-3}\right)\end{array}$ & $\begin{array}{l}\text { Average body } \\
\text { length } \\
\left(\mathrm{m} \times 10^{-2}\right)\end{array}$ & $\begin{array}{l}\text { Average weight- } \\
\text { to- length ratio } \\
\left(\mathrm{g} / \mathrm{cm}^{2}\right)\end{array}$ & $\begin{array}{l}\text { Average body } \\
\text { weight } \\
\left(\mathrm{kg} \times 10^{-3}\right)\end{array}$ & $\begin{array}{l}\text { Average body } \\
\text { length } \\
\left(\mathrm{m} \times 10^{-2}\right)\end{array}$ & $\begin{array}{l}\text { Average weight- } \\
\text { to- length ratio } \\
\left(\mathrm{g} / \mathrm{cm}^{2}\right)\end{array}$ \\
\hline & \multicolumn{3}{|c|}{ Primary examination } & \multicolumn{3}{|c|}{ Secondary examination $_{180}$} \\
\hline Group 1 & $\begin{array}{l}7.05^{*} \\
p=0.004\end{array}$ & $\begin{array}{l}6.117^{*} \\
p=0.004\end{array}$ & $\begin{array}{l}0.188^{*} \\
p=0.007\end{array}$ & 220.000 & 18.750 & 0.625 \\
\hline Group 2 & $\begin{array}{l}6.667^{*} \\
p=0.004\end{array}$ & 5.000 & $\begin{array}{l}0.268^{*} \\
p=0.010\end{array}$ & 192.500 & 17.833 & 0.596 \\
\hline Group 3 & $\begin{array}{l}7.183^{*} \\
p=0.004\end{array}$ & $\begin{array}{l}5.667^{*} \\
p=0.012\end{array}$ & 0.224 & 198.333 & 17.750 & 0.618 \\
\hline Group 4 & $\begin{array}{l}7.04^{*} \\
p=0.006\end{array}$ & 5.140 & $\begin{array}{l}0.266^{*} \\
p=0.006\end{array}$ & 157.600 & 17.323 & 0.526 \\
\hline Group 5 & 5.633 & 5.017 & 0.225 & 188.333 & 17.520 & 0.595 \\
\hline
\end{tabular}

* The difference between groups of large-weight rats and middleweight rats (control) is significant (within the 0.95 confidence interval). 
using Lambda scan mode. Emission spectrum peaks were detected at wavelengths ranging from $500 \mathrm{~nm}$ to $600 \mathrm{~nm}$ (Figure 1). Further, additional emission peaks were checked using tunable pulse scanning multi-photon Ti: Sapphire laser Chameleon Ultra. Various excitation wavelengths were applied in the detection window of $15 \mathrm{~nm}$, and a single emission peak was detected (Figure 2). Consequently, a single excitation wavelength of $488 \mathrm{~nm}$ and the detection range of
500-600 nm were used to obtain an optimal signal from $\mathrm{H} \& \mathrm{E}$ stained tissue sections.

Morphometric Parameters. The three-dimensional image obtained as a result of confocal scanning of the oral cavity mucosa samples allowed us to determine the exact size of each acanthotic overgrowth in any of its part. The length of a wave curve (e.g., L1 in Fig. 3) of acanthotic outgrowths, the number of the outgrowths, and the length of lower boundary,

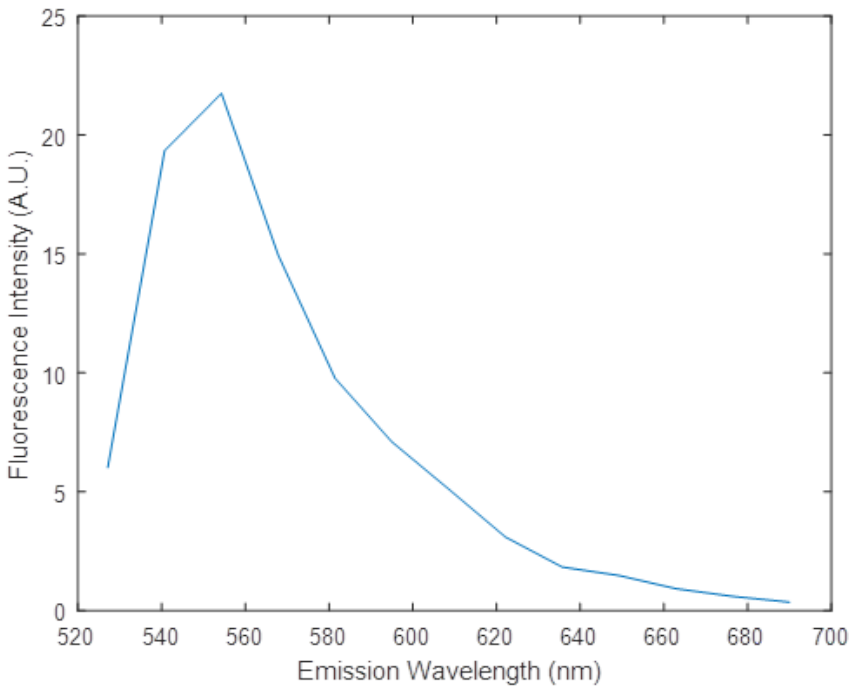

Fig. 1 Detection spectrum for the excitation wavelength of $488 \mathrm{~nm}$. Dependence of the fluorescence intensity versus wavelength at the single-photon excitation sections of tissue preparations experimental animals stained by hematoxylin and eosin. Emission spectra acquired by spectral scanning, implemented in standard Leica Confocal Software-Advanced Fluorescence (LAS AF) for confocal microscope Leica SP8 $-\ll \lambda^{2}$-scan» mode and post processed in the same software package (Quantify-Stack Profile).

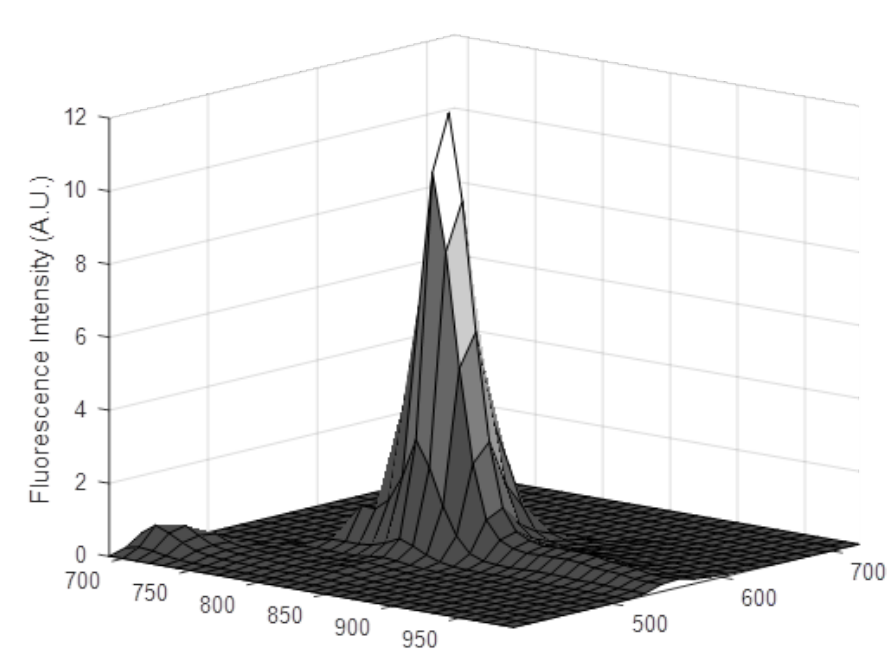

Excitation Wavelength (nm)

Fig. 2 Emission characteristics of hematoxylin and eosin stained specimen excited by multiphoton laser. Multiphoton laser was pulsing from $690 \mathrm{~nm}$ to $990 \mathrm{~nm}$ in a $10 \mathrm{~nm}$ step. The HyD detectors were turned to each wavelength in a bandpass window of $15 \mathrm{~nm}$.
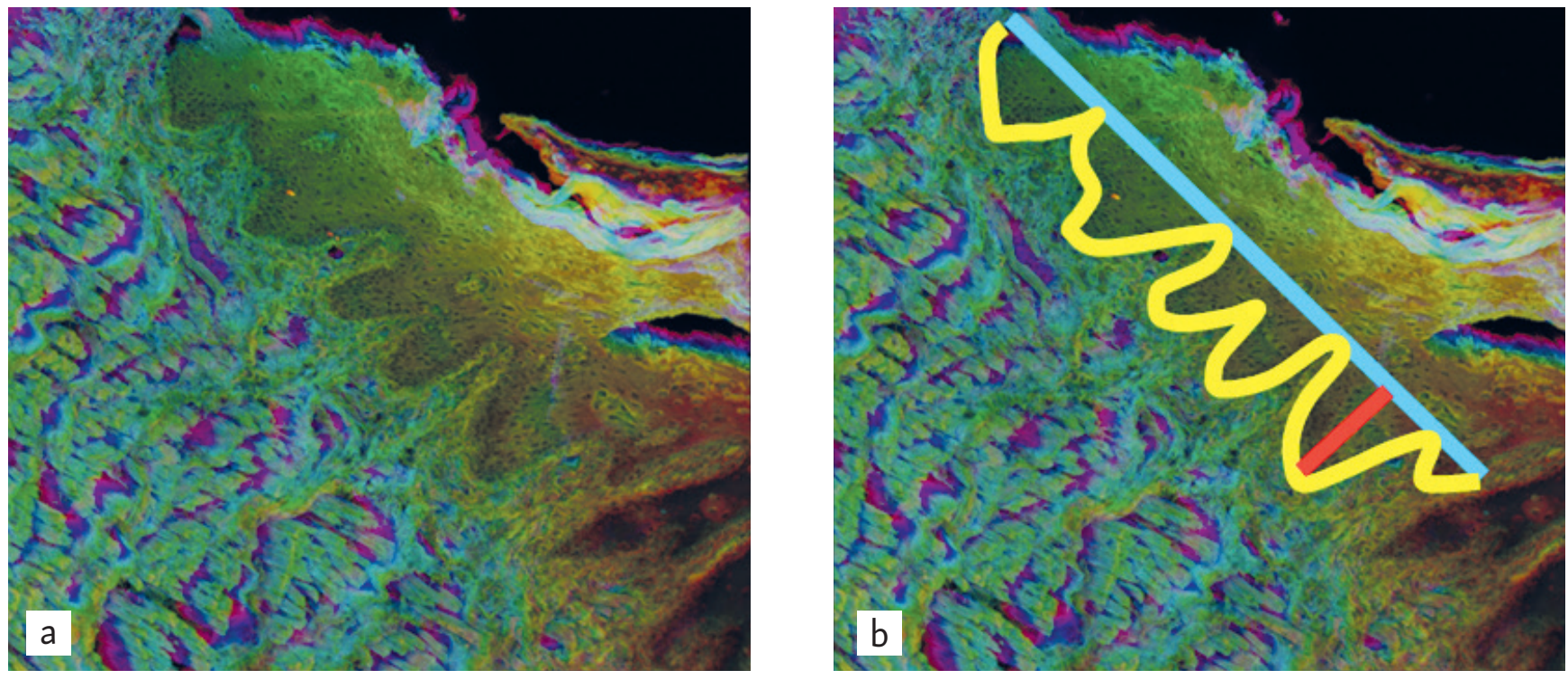

Fig. 3 (a) Fragment of mucous membrane epithelium off the mucobuccal fold from the projection area of the masticatory tooth roots in a 6-month-old WAG rat with intrauterine obesity and mothers' hypokinetic conditions (Group 4). Depth color coding of Maximum projection of color-coded z-stack (stack of confocal micrographs) (33 optical sections). The physical size of the visible regions $778.28 \times 763.96 \times 42.6 \mathrm{~m}$. H\&E stain. Objective ACS APO 40× NA1.15 Oil CS.

(b) The same as in (a), and a schematic diagram showing the acanthotic outgrowths. Yellow line, L1, depicts acanthotic outgrowth envelope. Blue line, L2, depicts the base of the acanthotic outgrowths, L1. Red line, $H$, is a schematic image of the acanthotic depth. 
Tab. 2 Results of morphometric studies of oral mucous in test animals.

\begin{tabular}{|l|l|l|l|l|l|}
\hline Groups under Study & $\begin{array}{l}\text { The number of analyzed } \\
\text { samples }\end{array}$ & Base L, rel. units & Height H, rel. units & H/L & L1/L2 \\
\hline Group 1 & 5 & 537 & 384 & 0.71 & 1.73 \\
\hline Group 2 & 9 & 474 & $512^{*}$ & $1.23^{*}$ & $2.71^{*}$ \\
\hline Group 3 & 8 & 317 & 297 & 0.90 & 2.10 \\
\hline Group 4 & 7 & 444 & 456 & 1.10 & 2.46 \\
\hline Group 5 & 8 & 430 & 302 & 0.68 & 1.70 \\
\hline
\end{tabular}

* The difference between the groups of large-weight rats and middleweight rats (control) is significant (within the 0.95 confidence interval).

on which the line of acanthotic outgrowths of epithelium rests (e.g., L2 in Fig. 3), were measured on the confocal stacks of the sections taken off the animals in the Macrosomic and the Control Groups using the Measure plugin in the Fiji program (27).

The acanthotic outgrowth is assumed to be an isosceles triangle with the height $\mathrm{H}$ and the base $\mathrm{L}$, and the data have been used to determine their average values (see, e.g., $\mathrm{H}$ line in Fig. 3). The values of $H$ and $L$ in relative units and as the $H / L$ and L1/L2 ratios are shown in the Table 2.

Statistical Analysis Technique. The differences in the means for each Macrosomic Group and Control Group pair and the multiple comparisons amongst Macrosomic Groups were analyzed with Mann-Whitney $U$ test runs at the $p £ 0.05$ level of significance with the Statistica 6.0. Each Group was comprised of 5-6 independent samples.

\section{RESULTS AND DISCUSSION}

Numerous narrow and deep acanthotic outgrowths (Fig. 3, 5) and densely located 'juvenile' epitheliocytes in the basal layer on the apex of the acanthotic protrusions are found in six-month-old animals, whose fetal macrosomia was due to intrauterine obesity (Groups 2, 4). The stratum spinosum contains numerous double-nucleous epitheliocytes, which

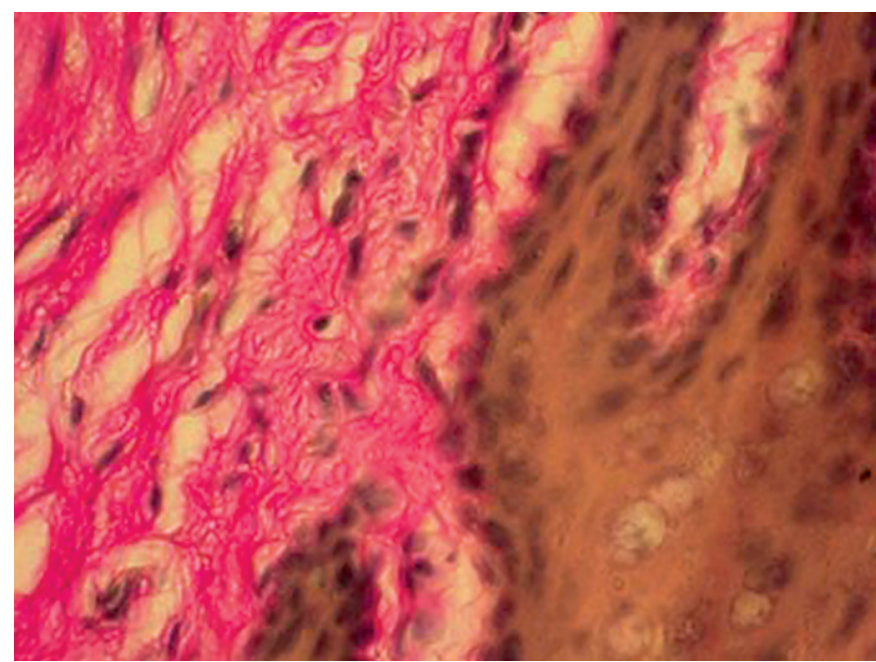

Fig. 4 Thin acanthotic outgrowth pattern in the mucosal epithelium in the oral cavity in an animal in the Control Group. Thin arrangement of epitheliocytes in the stratum basale. Van Gieson's stain, $\times 400$. indicates the stimulation of proliferation of epithelial cells. Furthermore, the stratum basale is partially absent, which proves the presence of intense proliferative processes.

Obtained morphometric attributes (Table 2) indicate a pronounced hyperproliferation of mucosa epithelium in the animals in macrosomic groups as compared to the animals in the Control Group (Fig. 4).

The animals in Group 1 with accelerated intrauterine growth and relatively decreased body weight (Fig. 5) have numerous double-nucleous epitheliocytes, partially absent basal membrane. The lamina propria of mucous is infiltrated with macrophages and lymphocytes, and morphometric indices (Table 2) reveal the acanthosis level comparable to that in the Control Group. In Group 1, the H/L and L1/L2 indexes reliably lower than the analogous indexes for Group 4 , and $L$ index is reliably higher than that for Group $3(p<0.05)$.

In animals with fetal macrosomia, which was due to intrauterine outgrowth acceleration, the hyperproliferation of the mucous membrane epithelium in the oral cavity is absent or it is pronounced a little.

The animals with harmonious intrauterine development (Group 3) have the hypoplastic epithelium. The lamina propria of mucosa in these animals is infiltrated with a greater number of macrophages and lymphocytes (Fig. 7) as compared to other animals, and the acanthosis level (Table 2) is higher than in the Control Group. The $L$ index for the animals in Group 3

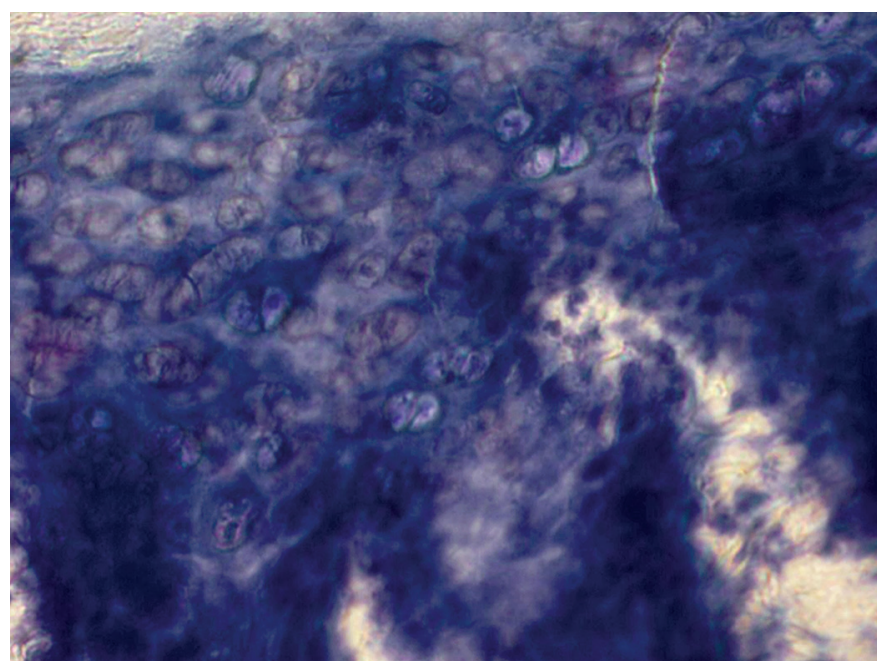

Fig. 5 Epithelium of the oral cavity mucosa in an animal from Group 1 (intrauterine acceleration). Epithelial hyperplasia; the nuclei of epitheliocytes in stratum spinosum are large and light, and nucleoli are visible. Gallocyanin-chromalum stain, $\times 400$. 


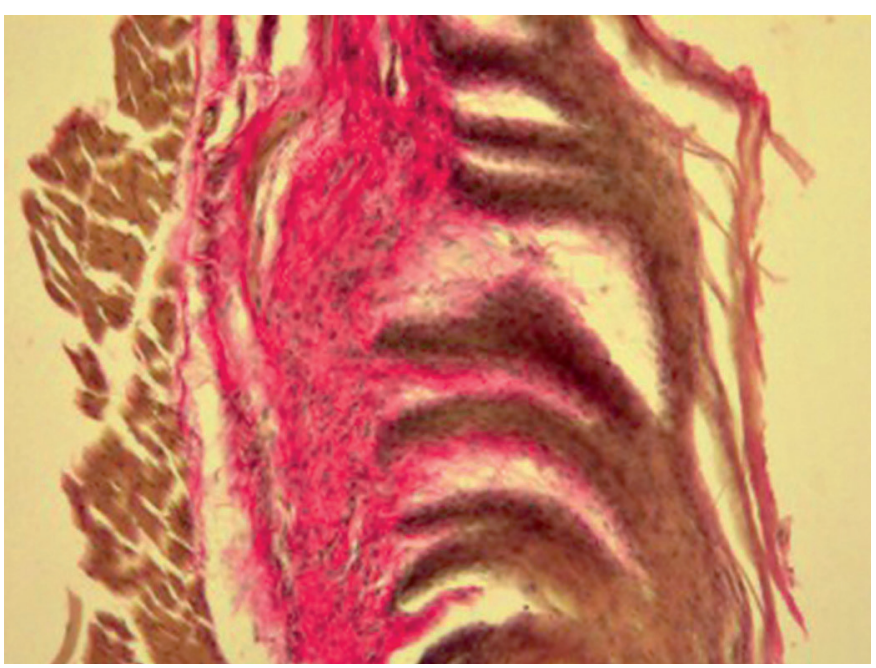

Fig. 6 Thin and long acanthotic outgrowth pattern in the mucosal epithelium in the oral cavity in an animal with intrauterine obesity (Group 2). Van Gieson's stain, ×100.

is reliably lower than those for Group 1 and Group 2, and the Hindex is reliably lower than that for Group $2(p<0.05)$.

The intensity of epithelial proliferation equal to that in the Control Group is found in 6-month-old animals with a harmonious intrauterine gain in the both body weight and height. These animals also have symptoms of acanthosis, although they are far less expressed against the background of epithelial layer thinning, which can be explained by the accelerated aging of epitheliocytes.

At the present time, the diseases of oral cavity mucous are very common. Many factors contribute to the development of various lesions of the oral cavity mucosa. We can assume that fetal macrocosmia with obesity causes an instability in the epithelium of the oral cavity mucosa, its rapid death and therefore more active stimulation of proliferation. The high intensity of epitheliocyte proliferation in macrosomic animals can cause increased predisposition to the development of different violations in oral cavity mucosa.

For instance, the susceptibility to epithelium hyperproliferation in oral cavity mucosa that we have revealed may be one of the causes of an increased predisposition to the development of acute herpetic stomatitis in children born with macrosomia (11).

We expect that the reproduction of this experiment on other linear animals will produce comparable results assuming that the maintenance of the standard conditions holds in repeated experiments, because the increased nutrition of a pregnant female promotes the weight gain of offspring in all animals. The scientific repeatability of this experiment is realized by the maintenance of the conditions for the each experiment and by the selection of macrosomic animals at birth, which have appeared to have a definite somatotype in our experiment.

\section{CONCLUSION}

The large body weight at birth could be an integral indicator of violations of the morphogenesis of oral cavity mucosa. In addition, the prevalence of intrauterine obesity or an

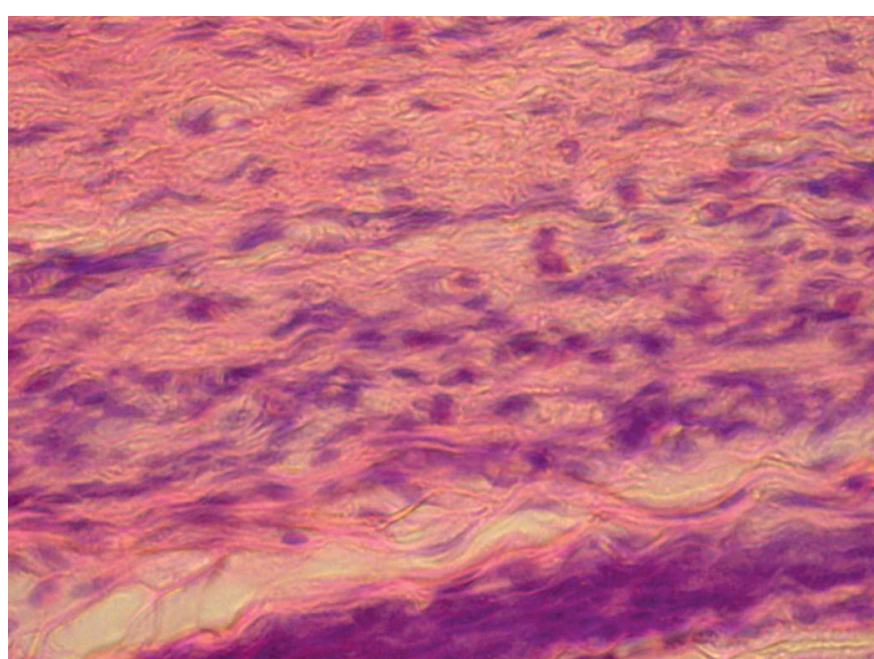

Fig. 7 Thick macrophage-lymphocytic infiltration of lamina propria in mucosa in an animal with fetal macrosomia with harmonious intrauterine development (Group 3). H\&E stain, $\times 400$.

accelerated body mass gain or the harmonious acceleration of body mass and height, have their own specific features in the microscopic picture of mucogingival fold of oral cavity mucosa epithelium in the 6-month-old experimental animals.

\section{ACKNOWLEDGEMENTS}

This work was supported by the Biolmaging Facility, Institute of Physiology, supported by the Czech-Biolmaging large RI project (LM2015062 funded by MEYS CR) and by the project Modernization and support of research activities of the national infrastructure for biological and medical imaging Czech-Biolmaging (CZ.02.1.01/0.0/0.0/16_013/0001775 funded by OP RDE).

The authors wish to thank Dr. Lucie Kubínová and Dr. Jiři Janáček for their helpful advice and comments and Dr. Daniel Hadraba for his advice in various technical issues.

\section{REFERENCES}

1. Barker DF. The developmental origins of adult disease. J Am Coll Nutr 2004; 23 Suppl 6: 588S-595S.

2. Gu $S, A n X$, Fang $L$, et al. Risk factors and long-term health consequences of macrosomia: a prospective study in Jiangsu Province, China. J Biomed Res 2012 Jul; 26(4): 235-40.

3. Winter JD, Taylor Y, Mowrer L, Wintera KM. Dulinbc MF. BMI at birth and overweight at age four. Obes Res Clin Pract 2016; 11(2): 151-7.

4. Donma MM. Macrosomia, top of the iceberg: the charm of underlying factors. Pediatr Int 2011; 53(1): 78-84.

5. Boney CM, Verma A, Tucker R, Vohr BR. Metabolic syndrome in childhood: association with birth weight, maternal obesity, and gestational diabetes mellitus. Pediatrics 2005; 115: e290-e296.

6. Godfrey KM, Inskip HM, Hanson, MA. The long-term effects of prenatal development on growth and metabolism. Semin Reprod Med. 2011 May; 29(3): 257-65.

7. Silva Idos S, De Stavola B, McCormack V. Birth size and breast cancer risk: re-analysis of individual participant data from 32 studies. PLoS Med 2008; 5: e193.

8. Hermann GM, Dallas LM, Haskell SE, Roghair RD. Neonatal macrosomia is an independent risk factor for adult metabolic syndrome. Neonatology 2010; 98(3): 238-44.

9. Huraseva, AB. Reproduktivnoe zdorove zhenschin, rodivshihsya s polyarnyimi znacheniyami massyi tela [Reproductive health of women born with polar body weight]. Mizhnarodnii endokrynolohichnii zhurnal 2010; 8: 106-15. 
10. Grischenko VI. Krupnyiy plod (kliniko-morfologicheskoe issledovanie). Kiev: Zdorovya, 1991: 183.

11. Yakovtsova AF, Sorokina IV, Aleshchenko IE Immune system of the human fetus in large and IUGR fetuses [in Russian]. Kharkov: BSF "Antiqua", 2004: 218.

12. Sorokina, AV. Krupnyj plod: mify i real'nost' (A large fetus: myths and realities). Rossiiskij vestnik akushera-ginekologa 2013; 13(4): 86-8. [in Russian].

13. Smolyar NI, Dubetska-Hrabous IS. Caries Risk Factors in Period of Initiation and Mineralization of Milk Teeth. [in Ukrainian] Profilaktychna ta Dytiacha Stomatologia. 2009; 1: 12-7.

14. Yokomichi H, Tanaka T, Suzuki K, Akiyama T, Okinawa Child Health Study Group, Yamagata Z. Macrosomic neonates carry increased risk of dental caries in early childhood: findings from a cohort study, the Okinawa child health study. Japan. PLoS One 2015; 10(7): e0133872.

15. Julihn A, Molund U, Drevsäter E, Modéer T. High birth weight is a risk factor of dental caries increment during adolescence in Sweden. Dent J 2014; 2(3): 118-33.

16. Ryabokon E, Garmash O, Nazarenko L, Babajanyan E. Dentists view on fetal macrosomia. Srodowisko a stan zdorowia jamy ustnej $X$ Konferencja Naukowo-Szkoleniowa, Naleczow, Polska, 27.04.2016. Naleczow, 2016: 70.

17. Garmash $\mathrm{O}$. An eruption pattern of deciduous teeth in children born with fetal macrosomia during the first year of life. Georgian Medical News 2017; 3(263): 14-23.

18. Garmash O, Ryabokon E. The Effect of Fetal Macrosomia on the Neonate and Infant Dental Health. International Journal of Clinical Dentistry 2017; 10(3): 200-10.
19. Analisis of oral health in newborns with macrosomia in Kharkiv city. Lik Sprava. 2017; 3-4: 122-6.

20. Kubínová L, Janáček J. Confocal stereology: an efficient tool for measurement of microscopic structures. Cell Tissue Res 2015; 360(1): $13-28$.

21. Kubínová L, Mao XW, Janáček J. Blood capillary length estimation from three-dimensional microscopic data by image analysis and stereology. Microsc Microanal 2013; 19(4): 898-906.

22. Janáček J, Čapek M, Michálek J, Karen P, Kubínová L. 3D microscopic imaging and evaluation of tubular tissue architecture. Physiol Res 2014; 63(1): S49-S55.

23. Eržen I, Janáček J, Kubínová L. Characterization of the capillary network in skeletal muscles from 3D data. Physiol Res 2011; 60(1): 1-13.

24. Capek M, Brůza $P$, Janácek J, Karen $P$, Kubínová L, Vagnerová R. Volume reconstruction of large tissue specimens from serial physical sections using confocal microscopy and correction of cutting deformations by elastic registration. Microsc Res Tech 2009; 72(2): 110-9.

25. Gubina-Vakulik GI. Patologichna anatomiia endokrynnyh zaloz plodu pry adaptatsii vagitnoi do dii okremyh seredovyshchnyh faktoriv (Pathological anatomy of the fetal endocrine glands in pregnant woman adaptation to the some environmental factors action). (Dissertation) [In Ukrainian] Ukraine, Kharkiv National Medical University 1994.

26. Garmash OV, Ryabokon EN. Gubina-Vakulyk GI. Method of modeling fetal macrosomia in experiment [In Ukrainian]. Patent for utility model. No. 123084 IPC. (Ukraine). Published 02.22.2018.

27. Schindelin J, Arganda-Carreras I, Frise E, et al. Fiji: an open-source platform for biological-image analysis. Nature Methods 2012; 9(7): 676-82. 